\title{
KETERAMPILAN SHOOTING PADA PERMAINAN PETANQUE
}

\author{
Muhammad Saiful Amri Al-khusaini ${ }^{1}$, Nurhidayat ${ }^{2}$ \\ Email : $\underline{\text { a810170077@ student.ums.ac.id }}{ }^{1}, \underline{\text { nur547@ums.ac.id }}{ }^{2}$
}

$\mathbf{1 , 2}$ Program Studi Pendidikan Olahraga, Fakultas Keguruan dan Ilmu Pendidikan, Universitas
Muhammadiyah Surakarta

\begin{abstract}
Abstrak
Penelitian ini dilatarbelakangi oleh belum maksimalnya kemampuan shooting game yang dimiliki oleh atlet petanque UMS, mengingat belum adanya persiapan model latihan untuk lebih mengembangkan kemampuan hasil shooting. Tujuan dari penelitian ini yaitu mengetahui Efek Penerapan Latihan Shooting Menggunakan Penghalang Terhadap Kemampuan Shooting game pada Atlet Petanque UMS. Tujuan latihan menggunakan penghalang adalah agar atlet terbiasa melakukan lemparan secara boules to boules. Metode yang digunakan yaitu eksperimen dengan menggunakan rancangan desain "one group pre test post test design". Penelitian ini menggunakan instrumen shooting game station 1, 2, 3, 4, 5 dan jarak lemparan $6 m, 7 m, 8 m$ dan $9 m$. Subjek dalam penelitian ini yaitu atlet petanque UMS berjumlah 15 orang. Sampel dipilih menggunakan teknik purposive sampling. Berdasarkan dari hasil perhitungan uji hipotesis dapat dilihat bahwa latihan shooting menggunakan penghalang mempunyai nilai signifikansi $0,000<0,05$ sehingga dapat dikatakan ada pengaruh yang signifikan dari latihan shooting menggunakan penghalang terhadap peningkatan hasil shooting game pada atlet petanque UMS. Dapat disimpulkan bahwa model latihan shooting menggunakan penghalang dapat meningkatkan hasil shooting pada atlet petanque UMS secara signifikan. Jika dilihat dari nilai rerata (mean) pretest sebesar 6,27 dan nilai rerata (mean) posttest sebesar 11,13. Hal tersebut menunjukan bahwa latihan yang dilaksanakan dapat memberikan peningkatan sebesar 4,86 .
\end{abstract}

Kata Kunci: Keterampilan; Petanque; Shooting.

\begin{abstract}
This research was motivated by the not yet maximal shooting game ability possessed by UMS petanque athletes, considering that there was no preparation of training models to further develop shooting abilities. The purpose of this research is to find out Effects of Implementing Shooting Practice Using Barriers on Shooting Game Ability in UMS Petanque Athletes. The purpose of training using a barrier is to get athletes accustomed to throwing boules to boules. The method used is an experiment using a "one group pre test post test design" design. This study used shooting game station 1, 2, 3, 4, 5 instruments and throwing distances of $6 \mathrm{~m}, 7 \mathrm{~m}, 8 \mathrm{~m}$ and $9 \mathrm{~m}$. The subjects in this study were 15 UMS petanque athletes. The sample was selected using purposive sampling technique.Based on the results of the calculation of the hypothesis test, it can be seen that the shooting practice using a barrier has a significance value of 0.0000 .05 so that it can be said that there is a significant effect of shooting practice using a barrier on the improvement of shooting game results in UMS petanque athletes. Can be concluded that<shooting practice model using a barrier can significantly improve shooting results in UMS petanque athletes. Ifseen from the mean value (mean) of the pretest of 6.27 and the mean value of (mean) of the posttest of 11.13. This shows that the exercise carried out can provide an increase of 4.86
\end{abstract}

Keywords: Skills; Petanque; Shooting. 


\section{A. Pendahuluan}

Petanque adalah permainan tradisional yang sudah dikembangkan dari permainan zaman yunani kuno pada abad 6 SM pada 1907. Olahraga ini dikenalkan oleh Jules Boule Lenior tepatnya di kota Le ciotat, provence selatan perancis. (Safitri et al., 2021) Petanque adalah jenis olahraga prestasi yang sudah di pertandingkan pada pertandingan resmi. Olahraga ini termasuk kedalam olahraga individu dan beregu. Petanque adalah olahraga asli yang dimainkan oleh masyarakat eropa selatan dan juga sudah resmi menjadi cabang olahraga pada tahun 1907 di perancis (Vernet, 2019). (Eler \& Eler, 2018) mengatakan bahwa olahraga petanque bisa dimainkan oleh semua usia dan gender baik laki-laki ataupun perempuan sehingga petanque bisa cepat berkembang dan sangat popular di eropa. Petanque merupakan olahraga yang sangat sederhana, permainannya bisa dilakukan dimana saja dan di tekstur lapangan apa saja seperti rumput, tanah, kerikil dan lainnya, untuk bisa memainakan olahraga petanque hanya membutuhkan lapangan seluas 6 x 12 meter (Gracia Sinaga \& ., 2019) (Gracia Sinaga \& ., 2019) Petanque yaitu permainan boules yang tujuan utamanya ialah melempar bola besi agar dekat dengan bola kayu atau jack dan kedua kaki berada didalam lingkaran atau circle saat melempar. Pada hakikatnya permainan petanque adalah mengumpulkan poin sebanyak 11 atau 13 poin dan mencegah pemain lawan untuk mendapatkan poin. Pada permainan petanque ada dua jenis pertandingan yaitu pointing game dan shooting game dan ada dua kategori jenis lemparan yaitu lemparan shooting dan lemparan pointing. lemparan pointing adalah lemparan untuk mendekati boka target, sedangkan lemparan shooting yaitu salah satu jenis lemparan yang berfungsi untuk menjauhkan bosi lawan dari jack atau boka, kemampuan shooting pada permainan petanque merupakan hal penting yang harus dimiliki atlet, jika kemampuan teknik shooting atlet lemah maka akan kesulitan untuk menyerang bosi lawan dan akan kesulitan mendapatkan poin. Pada pertandingan shooting game ada beberapa jarak yang harus di mainkan yaitu jarak $6 \mathrm{~m}$, $7 \mathrm{~m}, 8 \mathrm{~m}, 9 \mathrm{~m}$ dan poin yang bisa dihasilkan pada setiap jaraknya adalah antara 0 sampai dengan 5 poin.

(Bustomi et al., 2020) menjelaskan bahwa dari tujuan mekanikanya permainan petanque termasuk pada cabang olahraga yang bertujuan untuk mencapai accuracy optimal. Artinya olahraga Petanque merupakan permainan yang membutuhkan ketepatan dan akurasi yang maksimal, setiap lemparan yang di lakukan harus tepat mengenai sasaran. Berdasarkan pernyataan tersebut ketepatan adalah hal yang sangat berpengaruh pada nomor shooting, semakin baik accuracy setiap lemparan maka akan semakin banyak mendapatkan poin pada setiap rintangan pada nomor shooting. Kemampuan shooting pada olahraga petanque akan semakin baik apabila di latih sesuai dengan prinsip dan kaidah-kaidah latihan yang ada. Berdasarakan pengamatan yang telah dilakukan pada atlet petanque UMS pada setiap sesi latihan masih belum terfokus, banyak atlet yang berlatih hanya sekedar pemanasan dan langsung melakukan game, kurangnya melatih teknik shooting secara terprogram akan sangat berpengaruh pada kemampuan setiap atlet di pertandingan yang di mainkan. Pada nomor shooting game atlet petanque UMS yang bermain di kejuaraan nasional petanque semarang hanya mampu mendapatkan poin sebanyak 15 poin padahal pada nomor shooting, poin yang bisa dihasilkan maksimal adalah 100 poin hal ini menunjukan bahwa kemampuan shooting atlet petanque UMS masih lemah dan jauh dari kata baik. Dari permasalahan yang ada penulis ingin menerapkan latihan shooting menggunakan penghalang berupa ban bekas dengan tujuan setelah diterapkan latihan shooting menggunakan penghalang nantinya kemampuan shooting game atlet petanque UMS meningkat. Adapun manfaat dari penelitian yang akan dilakukan ini adalah memberikan informasi kepada pelatih atau atlet variasi latihan untuk meningkatkan kemampuan shooting atlet menggunakan latihan shooting dengan penghalang. Selain itu diharapkan dapat digunakan sebagai acuan untuk penelitian ke depan 
untuk pelatih, Pembina dalam upaya membahas cara meningkatkan kemampuan shooting atlet petanque.

\section{B. Metode}

Jenis penelitian yang dipakai yaitu penelitian eksperimen semu. Penelitian eksperimen digunakan untuk memperoleh kemungkinan hubungan antara sebab dan akibat variabel independen dan variabel dependen. Desain pada penelitian ini "One Groups Pretest-Posttest Design". Penelitian ini dilaksanakan dari awal juni hingga ahir juli 2021, bertempat di lapangan petanque UMS. Populasi pada penelitian ini yaitu atlet petanque pendidikan olahraga FKIP UMS. Sampel berarti salah satu bagian karakter dari populasi yang diteliti (Sugiyono, 2019). peneliti menggunakan teknik purposive sampling dalam memperoleh sampel, teknik purposive sampling merupakan cara memperoleh subyek dengan pertimbangan tertentu. Pertimbangannya antara lain (1) sudah terdaftar menjadi anggota MBO Petanque pendidikan olahraga FKIP UMS, (2) Berjenis kelamin Laki-laki, (3) Bersedia mengikuti proses penelitian. Instrumen tes yang digunakan adalah shooting game station 1,2,3,4,5 dan jarak $6 \mathrm{~m}, 7 \mathrm{~m}, 8 \mathrm{~m}$ dan $9 \mathrm{~m}$. Langkah pertama yang dilakukan adalah memberi tes awal kepada sampel yang sudah terpilih yang belum mendapat perlakuan atau pretest $\left(O_{1}\right)$. Setelah mendapatkan hasil dari pretest, maka dilakukan treatment atau perlakuan $(\mathrm{X})$ yang berupa latihan shooting menggunakan penghalang. Setelah dilakukan beberapa kali latihan, diberikan tes lagi atau posttest $\left(\mathrm{O}_{2}\right)$ untuk memahami tingkat kemampuan shooting

game. Sehingga didapatkan 2 hasil dari pretest dan posttest, kemudian data tersebut di analisa dan dibandingkan untuk bisa mengetahui seberapa besar pengaruh yang dihasilkan dari latihan shooting menggunakan penghalang. Sebelum melakukan perhitungan uji hipotesis, maka perlu melakukan uji prasyarat yaitu uji normalitas dan uji homogenitas. Uji normalitas merupakan sebuah uji yang menilai apakah data yang diujikan berdistribusi normal atau tidak. Sedangkan Uji homogenitas yaitu sebuah uji yang dilakukan untuk membuktikan bahwa sekumpulan data yang akan diuji berasal dari populasi yang sama (homogen). Untuk mengetahui apakah ada pengaruh yang signifikan maka dilakukan Pengujian hipotesis menggunakan Paired sampel T-test untuk membandingkan mean antara pretest dan posttest menggunakan bantuan program spss 21

\section{Hasil dan Pembahasan}

Penelitian ini dilaksanakan bertujuan untuk mengetahui Efek Penerapan Latihan Shooting Menggunakan Penghalang Terhadap peningkatan Kemampuan Shooting Atlet Petanque UMS. Penelitian ini diawali dari pengambilan data pretest yang berlangsung pada tanggal 9 juni 2021 dan diakhiri dengan pengambilan data posttest yang berlangsung pada tanggal 22 juli 2021. Data pretest dan posttest tersebut kemudian di analisis manggunakan bantuan program spss 21, Hasil penelitian dapat dideskripsikan sebagai berikut: Uji normalitas akan menguji hipotesis sampel tersebut berasal dari populasi yang berdistribusi normal, pengujian normalitas pada penelitian ini menggunakan uji Shapiro-Wilk. Hasilnya sebagai berikut:

Tabel 1. Hasil Analisis Uji Normalitas

\begin{tabular}{cccc}
\hline NO & Variabel & Asymp.Sig & Kesimpulan \\
1 & Pre Test & 0,169 & Normal \\
2 & Post Test & 0,124 & Normal \\
\hline
\end{tabular}


Dari hasil analisis diatas menunjukan bahwa nilai P dari variable tersebut semuanya > 0,05 maka hipotesis dapat dinyatakan diterima atau bersifat normal. Dari hasil tersebut, maka data variable dalam penelitian ini dapat dianalisis menggunakan statistic parametric. Uji Homogenitas bertujuan untuk membuktikan apakah varians dari variable tersebut sama (homogen). Jika nilai signifikansi $>0,05$ maka variable tersebut homogen, dan jika nilai signifikansi $<0,05$ maka variabel tersebut tidak homogen. Hasil perhitungan uji homogenitas disajikan pada tabel berikut.

Tabel 2. Hasil Analisis Uji Homogenitas

\begin{tabular}{ccc}
\hline Variabel & Nilai Signifikansi & Kesimpulan \\
Latihan Shooting menggunakan Penghalang & 0,152 & Homogen
\end{tabular}

Berdasarkan hasil perhitungan dari tabel diatas menunjukan bahwa nilai signifikansi $>0,05$ sehingga varians sampel tersebut bersifat homogen, maka hipotesis yang mengatakan varians dari variabel yang ada sama atau diterima. Maka dapat disimpulkan bahwa varians populasi tersebut bersifat homogen. Uji hipotesis yang dilakukan menggunakan analisis statistic paired sample t-test. Data dianalisis untuk menjawab hipotesis yang mengatakan adakah efek Penerapan Latihan Shooting Menggunakan Penghalang Terhadap Kemampuan Shooting Atlet Petanque UMS. Untuk melihat ada atau tidaknya Efek Penerapan Latihan Shooting Menggunakan Penghalang Terhadap Kemampuan Shooting Atlet Petanque UMS. Maka dilakukan pengujian hipotesis menggunakan paired sample t-tes yang dapat dilihat hasilnya pada tabel berikut.

Tabel 3. Uji Hipotesis

\begin{tabular}{ccccc}
\hline Variabel & Pre Test & Post Test & Sig. & Kesimpulan \\
\hline $\begin{array}{c}\text { Latihan Shooting menggunakan } \\
\text { Penghalang }\end{array}$ & 6.27 & 11.13 & 0.000 & Signifikan \\
\hline
\end{tabular}

Dilihat dari hasil analisis statistic berdasarkan tabel diatas menunjukan bahwa latihan shooting menggunakan penghalang memiliki nilai signifikansi $0,000<0,05$ maka dapat diartikan ada pengaruh yang signifikan dari latihan shooting menggunakan penghalang terhadap peningkatan kemampuan shooting game atlet petanque UMS. Jika dilihat dari nilai rerata (mean) pretest sebesar 6,27 dan nilai rerata (mean) posttest sebesar 11,13 mengalami peningkatan sebesar 4,86. Dapat disimpulkan bahwa latihan shooting menggunakan penghalang dapat meningkatkan kemampuan shooting game atlet petanque UMS

Pembahasan

Penelitian ini dilakukan untuk mengetahui Efek Penerapan Latihan Shooting Menggunakan Penghalang Terhadap Kemampuan Shooting Atlet Petanque UMS. Subjek yang digunakan adalah atlet petanque UMS. Berdasarkan hasil uji hipotesis diketahui bahwa latihan shooting menggunakan penghalang memiliki nilai signifikansi $0,000<0,05$ maka dapat diartikan ada pengaruh yang signifikan dari latihan shooting menggunakan penghalang terhadap peningkatan kemampuan shooting game atlet petanque UMS. Jika dilihat dari 
jumlah nilai rerata (mean) pretest sebesar 6,27 dan nilai rerata (mean) posttest sebesar 11,13 hal ini menunjukan bahwa latihan yang sudah dilaksanakan dapat memberikan peningkatan sebesar 4,86 untuk kemampuan shooting game dibandingkan sebelum diberikan treatment. Hal ini dapat dilihat dari grafik perbandingan perbandingan antara rerata pretest dan posttest sebagai berikut.

Grafik 1. Perbandingan Rerata Pre test dan Post test

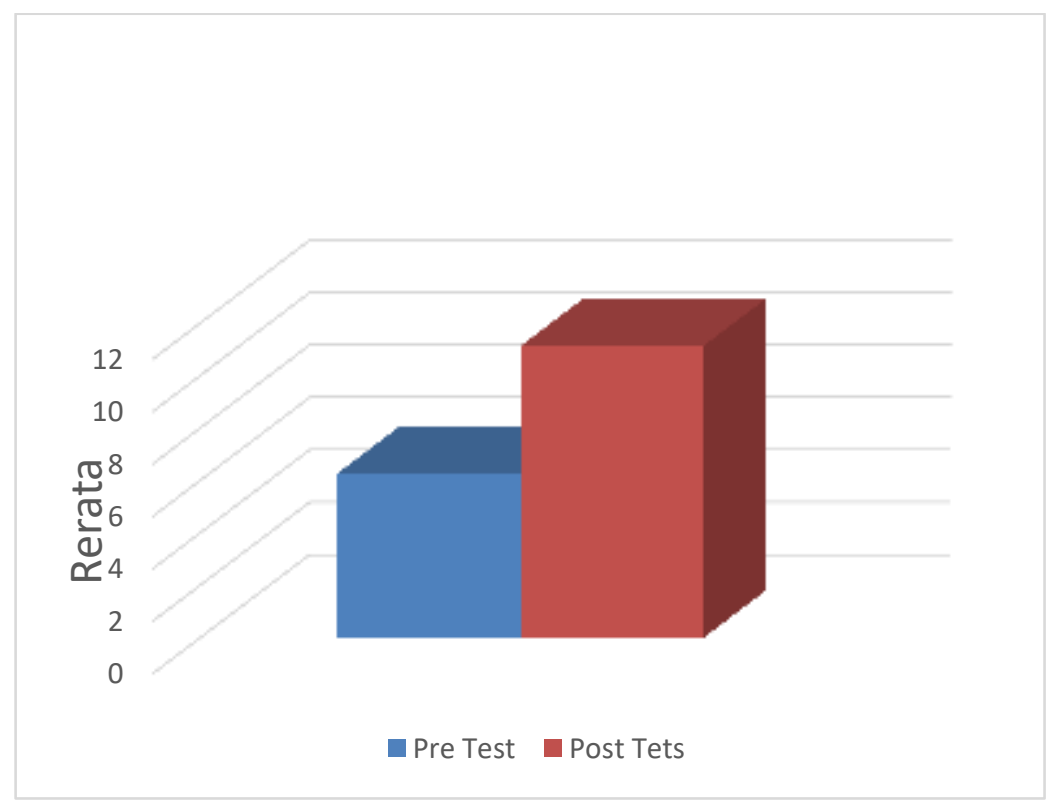

Hasil dari penelitian di atas menunjukan bahwa latihan shooting menggunakan penghalang dapat memberi kontribusi yang optimal terhadap peningkatan kemampuan shooting game atlet petanque UMS. Hal ini membuktikan seberapa besar peran latihan yang diberikan untuk meningkatkan kemampuan atlet, peningkatan kemampuan shooting game atlet dari kriteria cukup baik sebesar 4.86 ini memberi bukti bahwa latihan yang diterapkan sudah sesuai dengan prinsip - prinsip latihan serta memberikan dampak baik bagi kebutuhan atlet. Lathan shooting menggunakan penghalang mampu memberikan pengaruh yang signifikan terhadap kemampuan shooting game dikarena saat latihan atlet diberikan pembatas yaitu ban bekas sehingga atlet dipaksa untuk melakukan lemparan parabol sempurna dan menjadi tembakan secara boules to boules. Penelitian yang telah dilakukan oleh (Sutrisna et al., 2018) dengan judul "Model latihan Keterampilan shooting Olahraga Petanque Untuk Pemula" menjelaskan bahwa Model latihan Keterampilan shooting pada olahraga Petanque Bagi Pemula bisa diterapkan dan dikembangkan untuk kegiatan ekstrakurikuler yang ada disekolah, model latihan shooting pada permainan petanque bagi pemula yang sudah dikembangkan diperoleh hasil terdapat peningkatan hal ini dibuktikan pada analisis data hasil pretest dan posttest bahwa terdapat peningkatan yang signifikan antara sebelum diberikan treatment dan sesudah diberikan treatment.

Banyak sekali faktor yang menjadi pengaruh kemampuan teknik dasar atlet dalam permainan petanque. Kurangnya kemampuan shooting atlet harus dicari tau penyebabnya, minimnya model latihan shooting yang diberikan kepada atlet menjadi salah satu faktor yang mempengaruhi kemampuan teknik dasar shooting dalam permainan petanque. Oleh karena itu seorang pelatih dituntut untuk bisa memberikan berbagai macam variasi model latihan agar atlet bisa meningkatkan kemampuan teknik dasar shooting dengan benar, selain itu 
pemberian model latihan yang bervariasi juga menghindari atlet merasakan kejenuhan saat latihan. Pada permainan petanque, pointing dan shooting merupakan teknik dasar yang harus dimiliki oleh atlet. Akan tetapi teknik shooting adalah teknik yang sangat penting dengan tidak mengsampingkan kemampuan teknik pointing, teknik shooting dalam permainan petanque digunakan sebagai strategi menyerang karena bisa membuat bosi lawan untuk menjauhi boka. (Pelana et al., 2020) mengatakan keterampilan shooting merupakan salah satu teknik dasar pada permainan petanque, keterampilan shooting adalah keterampilan yang digunakan untuk mengusir bosi lawan dari boka. Namun disisi lain teknik shooting lebih sulit dikuasai ketimbang teknik pointing karena atlet dituntut untuk memiliki tingkat akurasi yang tinggi. (Nachin, 2013) menyatakan bahwa saat melakukan sebuah lemparan seluruh tubuh harus memiliki koordinasi yang baik serta posisi tubuh dan kaki harus stabil, hal ini merupakan tingkat kesulitan dalam teknik shooting. Oleh karena itu dalam pemberian latihan seorang pelatih harus mampu berinovasi agar atlet yang menjalani laihan dapat meninkatkan kemampuannya secara maksimal dan atlet tidak merasakan kejenuhan karena minimnya variasi latihan yang diberikan.

\section{Simpulan}

Berdasarkan hasil perhitungan analisa data dan pengujian hipotesis yang sudah dilakukan terdapat pengaruh yang signifikan dari latihan shooting menggunakan penghalang terhadap peningkatan kemampuan shooting game atlet petanque UMS. Dari hasil perhitungan menggunakan analisis statistik paired samples $t$ test menunjukkan bahwa latihan shooting menggunakan penghalang mempunyai nilai signifikansi $0,000<0,05$. Hal ini dapat diartikan bahwa ada pengaruh yang signifikan jika dilihat dari jumlah nilai rerata (mean) pretest sebesar 6,27 dan nilai rerata (mean) posttest sebesar 11,13 mengalami peningkatan sebesar 4,86. Dapat disimpulkan bahwa latihan shooting menggunakan penghalang dapat meningkatkan kemampuan shooting game pada atlet petanque UMS dibandingkan sebelum diberi latihan.

\section{Daftar Pustaka}

Bustomi, A. O., Hidayah, T., Okilanda, A., \& Putra, D. D. (2020). Analisis Gerak Pointing Pada Olahraga Petanque. Journal Sport Area, 5(1), 65-75. https://doi.org/10.25299/sportarea.2020.vol5(1).4807

Eler, N., \& Eler, S. (2018). A Study on Somatotype Profiles of the Players in Turkish Bocce National Team. Journal of Education and Training Studies. https://doi.org/10.11114/jets.v6i2.2940

Gracia Sinaga, F. S., \& . I. (2019). Analysis Biomechanics Pointing dan Shooting Petanque Pada Atlet TC PON XX PAPUA. Sains Olahraga : Jurnal Ilmiah Ilmu Keolahragaan, 3(2), 66. https://doi.org/10.24114/so.v3i2.15196

Hanief, Y. N., \& Purnomo, A. M. I. (2019). Petanque: Apa saja faktor fisik penentu prestasinya?. Jurnal Keolahragaan, 7(2), 116-125.

Isyani, I., \& Primayanti, I. (2021). Efektivitas Latihan Core Stability Terhadap Kemampuan Shooting Dalam Permainan Petanque. Gelora: Jurnal Pendidikan Olahraga dan Kesehatan IKIP Mataram, 6(2), 76-80.

Irawan, F. A. (2019). Biomechanical analysis of concentration and coordination on the accuracy in petanque shooting. ACTIVE: Journal of Physical Education, Sport, Health and Recreation, 8(2), 96-100.

Lubis, M. R., \& Permadi, A. G. (2020). Perbedaan Pengaruh Latihan Imagery Dan Tanpa Latihan Imagery Terhadap Peningkatan Kemampuan Shooting Game Atlet Petanque Undikma. Jurnal Ilmiah Mandala Education, 6(1). 
Laksana, G. B., Pramono, H., \& Mukarromah, S. B. (2017). Perspektif olahraga petanque dalam mendukung prestasi olahraga jawa tengah. Journal of Physical Education and Sports, 6(1), 36-43.

Muhammad, H. N., Wahono, B. S., Listiandi, A. D., \& Budi, D. R. (2020). Bunga Rampai Strategi, Proses, Evaluasi, dan Model Pembelajaran Pendidikan Jasmani, Olahraga, dan Kesehatan (PJOK) pada Era Pandemi Covid-19. Unesa University Press.

Mulya, G. (2020). Pengaruh Latihan Imagery dan Koordinasi terhadap Keterampilan Shooting pada Olahraga Pétanque. Jurnal of SPORT, 4(2).

Nachin, F. (2013). Petanque quand tu nous tiens. Franch.

Nurfatoni, A., \& Hanief, Y. N. (2020). Petanque: dapatkah koordinasi mata tangan, fleksibilitas pergelangan tangan, fleksibilitas togok dan keseimbangan memberi sumbangan pada shooting shot on the iron? Journal of Physical Activity (JPA), 1(1), $10-20$.

Okilanda, A. (2018). Revitalisasi Masyarakat Urban/Perkotaan Melalui Olahraga Petanque. Halaman Olahraga Nusantara (Jurnal Ilmu Keolahragaan), 1(1), 86-98.

Pelana, R., Achmad, S. H., \& Caca, I. S. (2020). Teknik Dasar Bermain Olahraga Petanque. PT Raja Grafindo Persada.

Safitri, A., Maghfiroh, I., Khafis, A., \& Panggraita, G. N. (2021). Profil Kebugaran Jasmani Atlet Petanque Kabupaten Pekalongan. Halaman Olahraga Nusantara (Jurnal Ilmu Keolahragaan), 4(1), 126. https://doi.org/10.31851/hon.v4i1.5070

Sugiyono, P. D. (2019). Metode Penelitian Pendidikan (Kuantitatif, Kualitatif, Kombinasi, R\&d dan Penelitian Pendidikan). Metode Penelitian Pendidikan.

Sutrisna, T., Asmawi, M., \& Pelana, R. (2018). Model Latihan Keterampilan Shooting Olahraga Petanque Untuk Pemula. JURNAL SEGAR. https://doi.org/10.21009/segar/0701.05

Sutrisna, T., Asmawi, M., \& Pelana, R. (2018). Model Latihan Keterampilan Shooting Olahraga Petanque Untuk Pemula. JURNAL SEGAR, 7(1), 46-53.

Vernet, C. (2019). Olahraga Petanque. Jakarta : Kridatama Andara Konsep.

Wahyudhi, A. S. B. S. E., Ismail, M., \& Arfah, M. (2021). Koordinasi Mata Tangan, Kekuatan Otot Lengan dan Kelentukan Pergelangan Tangan terhadap Keterampilan Shooting Atlet Petanque. SPORTIVE: Journal Of Physical Education, Sport and Recreation, 5(1), 1-8.

Wijayanto, A., \& Khurniawan, A. W. (2021). BUNGA RAMPAI Strategi Pembelajaran Pendidikan Jasmani Olahraga Dan Kesehatan Selama Pandemi Covid-19. 